\title{
HVMANITAS
}

\section{[Recensão a] Latim - Língua de cultura da Idade Média à Actualidade}

\author{
Autor(es): $\quad$ Urbano, Carlota Miranda
}

Publicado por: Faculdade de Letras da Universidade de Coimbra, Instituto de Estudos

URL

persistente:

Clássicos

DOI: $\quad$ DOI:http://dx.doi.org/10.14195/2183-1718_60_28

Accessed : $\quad$ 26-Apr-2023 14:53:05

A navegação consulta e descarregamento dos títulos inseridos nas Bibliotecas Digitais UC Digitalis, UC Pombalina e UC Impactum, pressupõem a aceitação plena e sem reservas dos Termos e Condições de Uso destas Bibliotecas Digitais, disponíveis em https://digitalis.uc.pt/pt-pt/termos.

Conforme exposto nos referidos Termos e Condições de Uso, o descarregamento de títulos de acesso restrito requer uma licença válida de autorização devendo o utilizador aceder ao(s) documento(s) a partir de um endereço de IP da instituição detentora da supramencionada licença.

Ao utilizador é apenas permitido o descarregamento para uso pessoal, pelo que o emprego do(s) título(s) descarregado(s) para outro fim, designadamente comercial, carece de autorização do respetivo autor ou editor da obra.

Na medida em que todas as obras da UC Digitalis se encontram protegidas pelo Código do Direito de Autor e Direitos Conexos e demais legislação aplicável, toda a cópia, parcial ou total, deste documento, nos casos em que é legalmente admitida, deverá conter ou fazer-se acompanhar por este aviso.

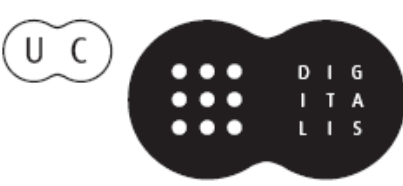


humanitas

\section{Vol. LX}

IMPRENSA DA UNIVERSIDADE DE COIMBRA

COIMBRA UNIVERSITY PRESS 
LATIM - LÍNGUA DE CULTURA DA IDADE MÉDIA À ACTUALIDADE. Actas do Encontro de Professores de Latim, Homenagem ao Professor Doutor Américo da Costa Ramalho, Coimbra, APLG, 2008, 101 pp. ISBN: 978-989-20-1092-2

Em Julho de 2006, a Associação de Professores de Latim e Grego prestou uma justa e digníssima homenagem ao Senhor Professor Américo da Costa Ramalho, Prof. Jubilado da Faculdade de Letras da Universidade de Coimbra, como quem celebra um verdadeiro patrono. A esta homenagem associaram-se muitos outros, amigos e discípulos do mestre. $\mathrm{E}$ que melhor homenagem prestar a um homem a quem a cultura portuguesa tanto deve, graças a longos anos ao seu serviço, no estudo e investigação e graças ainda à sua vontade que impulsionou uma escola de investigadores, do que promover um colóquio sobre o Latim, Língua de Cultura da Idade Média à actualidade? Com efeito, o especial mérito desse homem foi o de proporcionar à cultura portuguesa uma nova visão, porque mais verdadeira e profunda, da História do Humanismo Renascentista em Portugal, mas a sua orientação científica e o seu estímulo promoveram no trabalho de uma escola que moralmente gerou, o interesse pelo Latim e pela cultura clássica como chave fundamental para a compreensão da cultura portuguesa até aos nossos dias.

Em boa hora, decidiu a mesma Associação publicar as palavras que ouvimos neste colóquio, prolongando assim o desígnio da homenagem e deixando para o futuro o testemunho do louvor e, mais importante ainda, o testemunho vivo do exemplum homenageado. Coube ao Prof. Doutor José Geraldes Freire a redacção do prefácio que apresenta ao leitor $\mathrm{em}$ traços gerais os passos fundamentais da carreira do homenageado, em Portugal e no estrangeiro, esclarecendo alguns aspectos menos conhecidos e enumerando parte dos trabalhos científicos orientados pelo Prof. Costa Ramalho, evidenciando a extensão da sua obra científica quer em Portugal quer no estrangeiro.

O livro abre então com as palavras que proferiu na Sessão de Abertura a Dr. Isaltina Martins, Presidente da APLG (Associação de Professores de Latim e Grego) e antiga discípula do Prof. Ramalho. As suas palavras, aludindo ao inexcedível valor do legado clássico da cultura portuguesa e à importância vital da sua transmissão, fundamentam a iniciativa da APLG, de homenagear e prestar gratidão a quem "aos estudos clássicos e às línguas grega e latina se entrega com entusiasmo e fervor" (p. 22).

Segue-se o texto proferido pelo Prof. Doutor Amadeu Torres, da Universidade do Minho, "O Professor Doutor Américo da Costa Ramalho, o homem e a obra", que, seguindo o percurso biográfico do homenageado, esboça a sua "obra ímpar e pluriculturalmente exornante da extraordinária personalidade do Autor" (p. 23). Das provas académicas às publicações, passando pela orientação de trabalhos científicos, pela direcção de revistas e associações, pela organização e participação em encontros científicos assinaláveis, pelo labor nas várias Academias de que faz 
parte, pelo serviço de direcção da Faculdade, pelo ensino na cátedra de Coimbra, como em cátedras no estrangeiro, e pelo empenho pessoal "como defensor estrénuo da manutenção do Latim no Ensino Secundário" (p. 29), o Prof. Ramalho é apresentado como "exemplo para todos os docentes de clássicas"(p. 30) numa época que parece ameaçada de uma "amnésia planificada" em relação à sua herança cultural. O Prof. Amadeu Torres conclui presenteando o auditório com dois sonetos seus: "Supervisões pedagógicas" e "o eduquês".

Seguem-se depois as comunicações do painel Latim - Língua de Cultura - Da Idade Média à Actualidade. A abertura coube o Prof. Doutor Arnaldo Espírito Santo, da Universidade Clássica de Lisboa, que intitulou a sua reflexão: "O Latim como Língua de cultura na Idade Média, recte uiuendo recte loquendo". Este ideal de Humanismo e de cultura constitui o núcleo da sua reflexão em torno do Renascimento Carolíngio com a sua longa influência na cultura ocidental, mostrando como a "aposta no triuium...no studium litterarum" de Carlos Magno, proporcionou a emergência de uma nova cultura bem firmada no conhecimento dos textos "oferecendo a base de sustentação a uma ideia de Europa....apoiada numa língua de cultura universalizante" (p. 43).

A segunda conferência do painel é da Prof. Doutora Nair Castro Soares, da Universidade de Coimbra: "Cataldo Parísio Sículo «educador da nobreza portuguesan". Como sugere o título, o seu estudo centra-se na figura daquele que, depois da investigação do Prof. Costa Ramalho é considerado o introdutor do Humanismo em Portugal. A Prof. Nair Castro Soares, porém, a propósito do perfil exaustivo que nos desenha do humanista revelado pelo Prof. Costa Ramalho, descobre-nos o perfil deste outro humanista, seu mestre, evocando a riqueza e a variedade da sua obra com lata amplitude cronológica, os inúmeros prémios que reconhecem o seu mérito, os seus discípulos mais distintos, alguns deles de saudosa memória, e o lado mais humano e próximo do professor cujas qualidades recordou: "a acessibilidade e a franqueza de trato, essa faceta saudável e optimista, essa coerência de vida, (...) essa pujante combatividade na luta pela valorização da cultura e da ciência..." (p. 47).

Também discípula do homenageado é a Prof. Doutora Virgínia Soares Pereira, da Universidade do Minho, autora do texto que se segue: "Do Grego e do Latim como Línguas de Cultura". As suas palavras começam por evocar o magistério do Prof. Ramalho no Grego e nos clássicos latinos, na Universidade mas também ainda nos bancos do Liceu, através de obras de carácter pedagógico e centram-se depois numa interessante reflexão sobre a fecunda simbiose entre as culturas grega e latina e entre as línguas que as veiculam, o grego e o latim, num percurso que vai desde a Antiguidade aos nossos dias.

Encerra este painel a intervenção do Prof. Doutor João Nunes Torrão, também ele discípulo do Prof. Ramalho e hoje Professor da Universidade de Aveiro. As suas palavras fazem uma radiografia ao estado dos Estudos Clássicos 
entre nós: "Os Estudos Clássicos na Actualidade". Salientando as notas mais positivas a registar, como o bom acolhimento de temáticas clássicas nos grandes meios de comunicação e, mais positivo ainda, o facto de termos hoje como nunca nos nossos dias "tanta gente com tantas habilitações nesta área" (p. 85), o Prof. Torrão encerra a mesa redonda com uma nota optimista sem omitir os aspectos mais negativos do cenário actual que se revela francamente paradoxal. Dispomos de recursos humanos bem qualificados nos estudos clássicos, mas retiramos às gerações mais novas a possibilidade de acesso ao legado cultural clássico e às línguas que lhes permitiriam um acesso directo às fontes. $O$ entusiasmo das suas palavras finais não pode deixar de nos contagiar e colher boa resposta ao desafio que elas nos lançam.

A sessão de encerramento do encontro coube à também discípula do Prof. Ramalho, Vice-Presidente da APLG, a Mestre Teresa Geraldes Freire. As suas palavras, além de reafirmarem a gratidão pela obra e pelo exemplo do Prof. Costa Ramalho, empenham-se numa luta denodada contra o que chama uma "desertificação intelectual" (p. 93) que ameaça e já fere o nosso meio cultural em que o ensino do Latim nos actuais curricula do Ensino Secundário cai no esquecimento, acessível apenas a futuros alunos de Línguas e Literaturas e simplesmente vedado aos que pretendem estudar História, Direito, Filosofia, etc... As suas preocupações em relação ao futuro, porém, encontram esperança no pensamento optimista de que atravessamos apenas mais um ciclo e que também a superação desta crise "se tornará um dia inevitável" (p. 95).

Em jeito de chave de ouro, encerra a publicação que merecidamente traz a mais vasto público esta homenagem, uma primorosa composição poética latina, da autoria do Prof. Amadeu Torres (Resalutationis Carmen) e a sua versão em Português (Ode Sáfica), com que o poeta quis saudar o amigo e com que a APLG brindou os participantes do almoço-convívio que encerrou o programa.

Carlota Miranda Urbano

Lopes, Rodolfo Pais Nunes, Pseudo-Homero, Batracomiomaquia - A guerra das rãs e dos ratos. Introdução e tradução do grego, Coimbra, Colecção Fluir Perene, 2008. 71 pp. ISBN 978-989-95751-2-7

A Batracomiomaquia constitui o segundo livro da colecção Fluir Perene e abre a secção de traduções de obras clássicas. $O$ volume está organizado em duas partes, correspondentes a uma introdução geral (pp. 15-41) e à tradução propriamente dita (pp. 43-64). Acresce ainda um "Índice dos nomes das personagens" (pp. 67-71) que, sendo embora pouco extenso, dadas as reduzidas dimensões da obra, se revela bastante útil, porquanto apresenta a versão grega da forma como as personagens são designadas e explica o sentido destes 'nomes falantes', que contribuem, obviamente, para a natureza paródica da Batracomiomaquia. Embora o texto original 